\section{Glykierung, nichtenzymatisch}

K. J. Lackner ${ }^{1}$ und D. Peetz ${ }^{2}$

${ }^{1}$ Institut für Klinische Chemie und Laboratoriumsmedizin, Universitätsmedizin Mainz, Mainz, Deutschland

${ }^{2}$ Institut für Labormedizin, Helios Klinikum Berlin-Buch, Berlin, Deutschland

Englischer Begriff non-enzymatic glycation

Definition Kovalente, nicht enzymkatalysierte Bindung eines Kohlenhydrats, meist $>$ Glukose, Fruktose-1,6-Diphosphat (s. > Fruktose) oder Glukose-6-Phosphat an eine freie Aminogruppe eines Proteins.
Beschreibung Ketogruppen von Kohlenhydraten können mit den Aminogruppen von Proteinen (N-terminal oder $\varepsilon$-Aminogruppen von Lysinen) eine Schiff'sche Base (Aldimin) bilden. Diese Reaktion ist reversibel und hängt im Wesentlichen von der Konzentration der beteiligten Moleküle und dem $\mathrm{pH}-W e r t \mathrm{ab}$. Durch eine Amadori-Umlagerung ( $\triangleright$ Amadori-Reaktion) entsteht aus der Schiff'schen Base ein Ketoamin, das dann stabil ist (s. a. > Fruktosamin).

\section{Literatur}

Löffler G (2014) Pathobiochemie des Kohlenhydratstoffwechsels. In: Heinrich PC, Müller M, Graeve L (Hrsg) Löffler/Petrides Biochemie und Pathobiochemie, 9. Aufl. Springer, Berlin/Heidelberg, S 222-225 